\title{
Impact of COVID-19 on the production and consumption of agricultural food
}

\author{
Michael Il'in ${ }^{1, *}$, Lyudmila Kalinina ${ }^{1}$, Inga Zelenskaya ${ }^{1}$, Nikolaj Kalinin $^{1}$, Ol'ga Vlasenko ${ }^{1}$, Sof'ya Trufanova ${ }^{1}$, and Natal'ya \\ ZHdanova $^{1}$ \\ ${ }^{1}$ Federal State Budgetary Educational Institution of Higher Education "Irkutsk State Agrarian University named after A.A. Ezhevsky ", \\ Russia
}

\begin{abstract}
According to the United Nations, the consequences of the coronavirus pandemic are unique and their further development is unpredictable, which in turn makes planning the economy difficult. The coronavirus pandemic has had an impact on the development of the food market, changes in the functioning of all its components will continue significantly, but to a greater extent this will affect the interaction between producers and consumers, as well as their economic condition. One of the ways to reduce the negative consequences of the coronavirus pandemic is their informed assessment. This assessment, first of all, should include an analysis of the economic condition of producers and consumers of food products, taking into account the main factors of negative impact on their economic condition. This article proposes a methodological approach that includes an algorithm for studying changes in supply and demand for food products as a consequence of the impact of the coronavirus pandemic. Using the proposed methodological approach, the authors conducted a sociological survey of citizens living in the Irkutsk region, as a result of which the main consequences of the coronavirus pandemic, affecting the formation of demand for food, were identified, as well as the method of expert assessments identified problems and possible ways to overcome them among manufacturers.
\end{abstract}

\section{Introduction}

According to the United Nations, the consequences of the coronavirus pandemic are unique, and their further development is unpredictable, which in turn makes planning the economy difficult.

The report of the International Monetary Fund "Prospects for the development of the world economy" notes that the consequences of the coronavirus pandemic were more negative than previously planned, in the future this will lead to a slower pace of economic recovery in the world. [1].

Against the backdrop of a general downturn in the global economy, risks associated with hunger, food shortages and unemployment are sharply increasing. For example, according to estimates by the International Labor Organization, the Food and Agriculture Organization, the International Fund for Agricultural Development and the World Health Organization, tens of millions of people are at risk of falling into extreme poverty, and the number of undernourished, which is currently estimated at about 690 million people, could rise by by the end of 2020 by 132 million [1].

In addition, there are risks associated with the threat of disruption of food supplies due to the unavailability of the food system to function in a pandemic. Border closures and trade restrictions impede farmers' access to global markets. The millions of agricultural workers who effectively feed the world, live on the brink of poverty, are malnourished, have serious health problems, and suffer from insecurity and insecurity at work. Many of them are forced to continue working in a pandemic, exposing themselves and their families to additional risks.

Immediate and targeted actions to save lives and preserve livelihoods, according to the authors of the statement, should include expanding social protection by covering socially vulnerable and low-paid workers with health services, including migrants. Particular attention should be paid to the situation of women, who are often in low-paid jobs.

Countries that were already experiencing humanitarian crises or emergencies at the time of the outbreak of the pandemic are especially vulnerable to the negative impact of COVID-19. It is extremely important for such states that aid reaches the most needy segments of the population as soon as possible. [2].

According to Russian experts, the coronavirus pandemic has had a significant impact on the development of the domestic food market. Firstly, there were changes in the structure of food consumption and purchasing power; secondly, new sanitary standards were of no small importance, resulting in difficulties in production and supply chains, which affected the profitability of agricultural producers and food prices.

\footnotetext{
* Corresponding author: eci38@yandex.ru
} 
In addition to the main problems that Russian food producers and consumers had to face during the coronavirus pandemic, experts also noted positive aspects related to state support for the population, the development of new types of retail trade and an increase in demand for certain types of food products. [3].

For example, retail prices for buckwheat groats in Russia from November 2019 to October 2020 increased by $46.2 \%$.

According to Rosstat and Nielsen, in the territory of the Russian Federation in 2020, a number of food products became the leaders in sales in physical terms against the background of a sharp rise in their prices.

An expert in the field of assessing and analyzing traffic flows Watcom recorded a sharp drop in traffic in shopping centers. At the same time, cloud service provider NGENIX pointed to a steady increase in readyto-eat and food orders in the second half of 2020 [4].

\section{Materials and Methods}

The coronavirus pandemic has had an impact on the development of the food market, in the future there will certainly continue to be changes in the functioning of all its components, but to a greater extent this will affect the interaction between producers and consumers, as well as their economic condition. One of the ways to reduce the negative consequences of the coronavirus pandemic is their informed assessment. This assessment, first of all, should include an analysis of the economic condition of producers and consumers of food products, taking into account the main factors of negative impact on their economic condition.

As a methodological approach to assessing the consequences of the coronavirus pandemic, it is advisable to build a certain research algorithm, which includes:

- analysis of changes in demand for the main types of food products;

- analysis of changes in the structure and size of income of the population;

- assessing the psychological impact of the pandemic;

- analysis of the effectiveness of various forms and methods of state support for consumers of food products and methods of their state support;

- analysis of the economic condition of food producers.

In our opinion, it is necessary to use a sociological survey and the method of expert assessments as research methods. In the future, this will allow in a short time to objectively assess the main directions for reducing the negative consequences of the coronavirus pandemic at both the micro-, meso- and macro levels.

\section{Results}

In September-October 2020, employees of the Department of Economics of Agroindustrial Complex of the Federal State Budgetary Educational Institution of Higher Education "Irkutsk State Agrarian University named after A.A. Ezhevsky", a sociological study of the population of the Irkutsk region was carried out, as well as the heads of agricultural enterprises and officials of the executive and legislative authorities of the region and municipalities were attracted and interviewed as experts.

Citizens of all ages and municipalities of the Irkutsk region took part in the sociological survey. The survey revealed that most of the region's population $(67.9 \%)$ personally felt the effects of the coronavirus. Most of the residents of the Irkutsk region have a worsening financial situation, but the consumption of basic food products, as well as preferences in them, remained at the same level. The sociological survey data are presented in Figures 1-11.

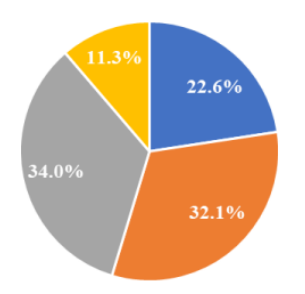

- 0-18 = 19-34 = 36-64 =65 and more

Fig. 1. Answers to the question "Specify your age".

As seen in Fig. 1 the survey was mainly attended by citizens of working age (more than 66\%). To the question "Specify your age" $34 \%$ of the respondents are citizens from 19 to 34 years old, $32.1 \%$ - citizens from 35 to 64 years old.

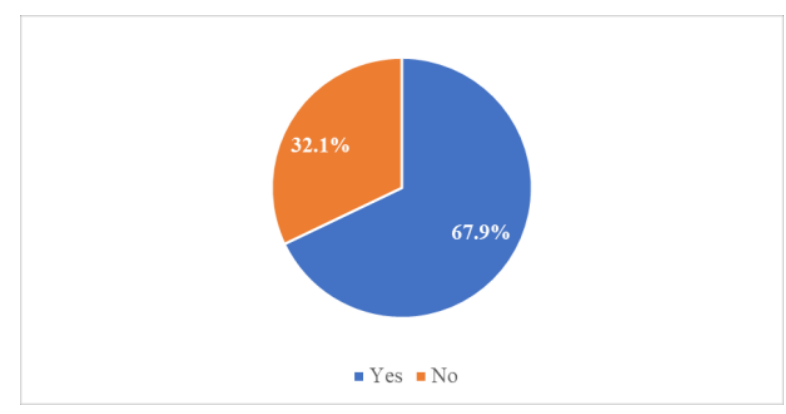

Fig. 2. Answer to the question "Have you personally or your family felt the consequences of COVID-19".

Answering the question "Have you personally or your family felt the consequences of COVID-19?" The majority (67.9\%) answered positively (Fig. 2).

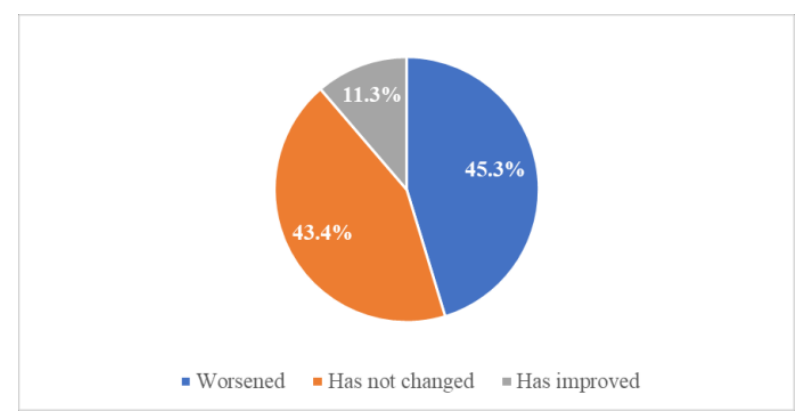

Fig. 3. Answer to the question "Has your (your family's) financial situation changed during the pandemic?". 
According to Fig. 3 only $11.3 \%$ to the question "Has your (your family's) financial situation changed during the pandemic?" Answered about the improvement of the financial situation, however $45.3 \%$ stated about its deterioration.

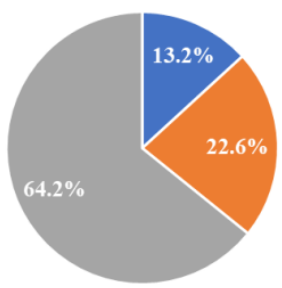

- Increased - Decreased = Remained the same

Fig. 4. Answer to the question "Has food consumption changed during the pandemic?".

Despite the deterioration in the financial situation of the majority of the respondents, as can be seen from Fig. 4 , the majority of citizens stated that the volume of consumption of basic food products during the pandemic did not change (Fig. 4)

Most of the citizens did not experience difficulties in purchasing food, but the psychological state was disturbed due to the fear of contracting an infection when visiting stores. This fact is also confirmed by the fact that in most cases food purchases were made in large stores (supermarkets) and convenience stores, home delivery was less in demand in the Irkutsk region.

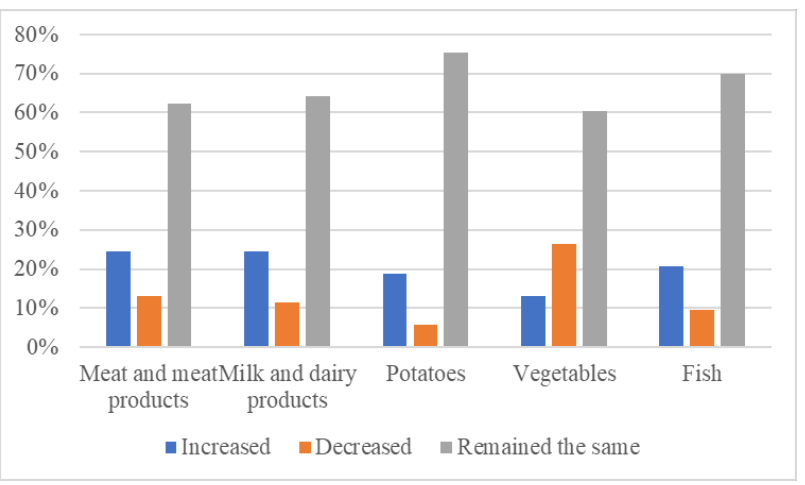

Fig. 5. Answer to the question "Have your preferences in food consumption changed by main types?".

As seen in Fig. 5 the consumption of potatoes and fish changed to a lesser extent, more than $20 \%$ of the respondents had an increase in the consumption of vegetables and a decrease in consumption and a decrease in the consumption of livestock products.

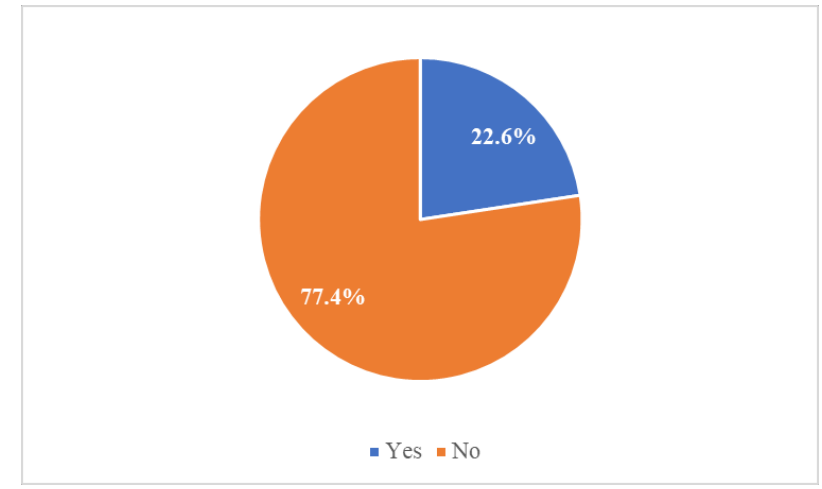

Fig. 6. Answer to the question "Did you (your family) experience difficulties when shopping for food during the pandemic?".

According to Fig. 6, despite the stable consumption of basic foodstuffs, the majority of the respondents experienced difficulties when shopping for foodstuffs.

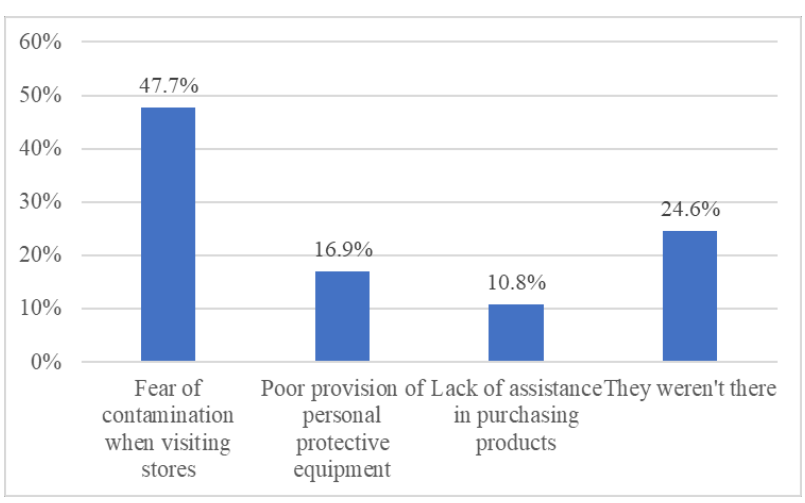

Fig. 7. Answer to the question "What difficulties arose during the pandemic".

The main problem during the pandemic was the fear of infection when visiting stores (Fig. 7), to a lesser extent, the lack of personal protective equipment and assistance with shopping in connection with the pandemic was noted.

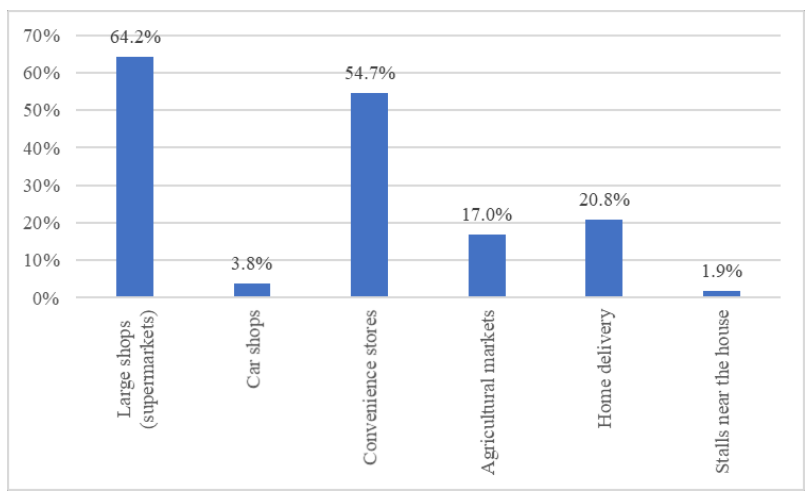

Fig. 8. Answer to the question "Where did you mainly buy food during the pandemic?".

According to Fig. 8 most of the interviewed citizens continued to make purchases in large stores (supermarkets), as well as stores located near their residence. 
On a positive note, it can be noted that $54.7 \%$ of those surveyed during the pandemic were engaged in physical culture and sports, which, in turn, had a positive effect on the psychological state (Fig.9).

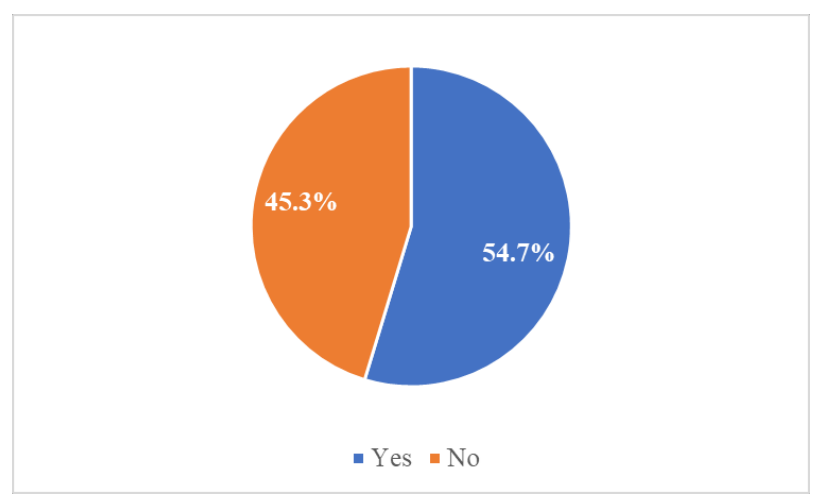

Fig. 9. Answer to the question "Have you been involved in physical culture and sports during the pandemic?".

The influence of government influence on food consumers can be characterized as moderate. To a greater extent, payments for children can be noted.

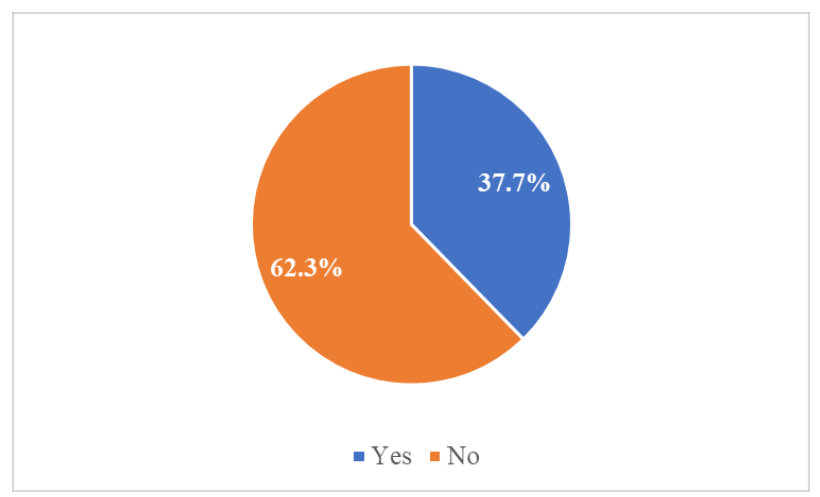

Fig. 10. Answer to the question "Did you (your family) receive government support during the pandemic?".

As seen in Fig. 10 more than half of citizens (62.3\%) did not receive government support during the pandemic.

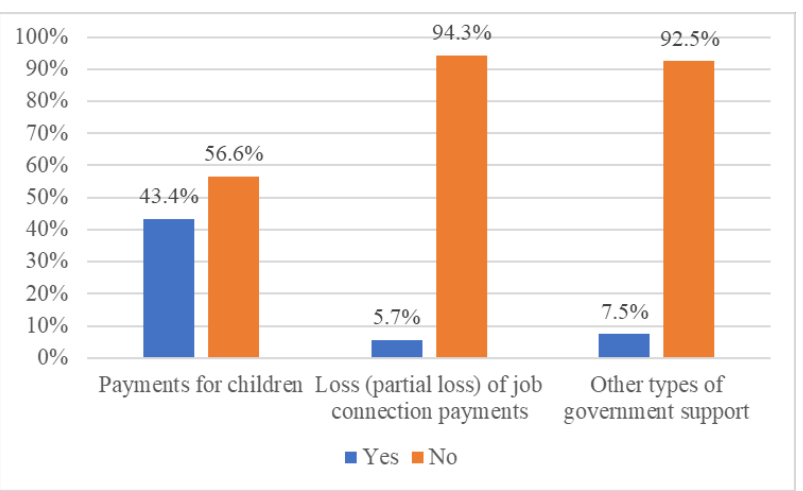

Fig. 11. Answer to the question "Has government support influenced you (your family)?".

However, among the respondents who received assistance from the state during the pandemic, financial assistance was noted in the form of payments for children (Fig. 11).
According to the results of a sociological survey of the population of the Irkutsk region, the following negative consequences of the pandemic can be distinguished:

- deterioration of the financial situation of a large number of citizens;

- the presence of psychological problems associated with the fear of contracting the virus when shopping for food, while there is a low demand for home delivery;

- low level of state support for the population.

On the positive side, there is a stable demand for food and a good psychological mood of the population amid a pandemic.

\section{Discussion}

According to experts, since the beginning of the development of the pandemic, state support for agricultural producers of small businesses to smooth out the consequences of the introduction of restrictive measures has not been provided.

In the Irkutsk region, the amount of state support for small agricultural business tended to decrease and the conditions for its provision became more stringent. In addition, the unpreparedness and slowness of the regional agro-industrial complex administration to make timely managerial decisions on interaction with small agricultural businesses created additional difficulties in solving economic problems and did not contribute to the development of this business using the state support tool. At the same time, state support for medium and large agricultural businesses increased, not related to the consequences of the pandemic.

The restrictive measures caused by the pandemic did not significantly affect the course of agricultural work (sowing and harvesting, caring for farm animals, etc.). There was no decrease in the number of people employed in agriculture during the pandemic.

It should be noted that agricultural producers faced difficulties in selling their products due to a decrease in population demand. At the same time, there were superimposed consequences associated with an increase in prices for imported capital goods for agriculture.

According to experts, there have been no changes in agricultural production due to the coronavirus pandemic. However, there were negative consequences for enterprises engaged in the processing of agricultural products, due to a decrease in the population's demand for food, which, in turn, led to a disruption in the supply chains in its promotion to the market.

In addition, the experts noted that the state support provided to the population during the pandemic was effective and achieved its goal, since for individual people it turned out to be the only source of income that could be used to purchase food and other goods and services.

As experts' suggestions, it can be noted that in order to maintain demand for agricultural products, it is necessary to establish fixed prices for the main food products of local agricultural producers sold to the end consumer in retail trade, which would increase the 
availability of food for vulnerable segments of the population. As these goods are sold in the retail network, it is necessary to reimburse the costs of these goods to agricultural producers as soon as possible (within 10 days) from the regional budget.

\section{Conclusion}

In conclusion, the experts noted that due to the coronavirus pandemic, agricultural producers have changed their approaches to planning economic activities under conditions of uncertainty. On the one hand, they are influenced by a possible further decrease in the expected demand for products, and on the other hand, by the need to respond quickly to changes in the volume and structure of production, to redistribute available production resources, which is quite difficult in agriculture, and sometimes impossible.

\section{References}

1. IMF warns of 4.9 percent contraction in global economy this year, UN Russian News Service on June 24 (2020)

2. COVID-19 pandemic: Humanitarian crisis is getting closer, UN Russian News Service (13 October 2020)

3. A. Belaya, Mode of increased unavailability, What agricultural problems did the coronavirus reveal, Agroinvestor (4 August 2020)

4. How the pandemic changed the Russian economy, Infographics, RBC (17 November 2020)

5. M.S. Ilin, L.A. Kalinina, Trends of development of world market and russian market of poultry meat and products of its processing, Topical issues of agriculture, 3, 37-45 (2012)

6. M.S. Ilin, L.A. Kalinina, Prospects for development of the regional meat market, International scientific and practical conference dedicated to the 110th anniversary of the birth of A.M. Kazansky, 37-42 (2012)

7. T. Buzina, Ya. Ivanyo, M. Polkovkaya, Multicriteria problem with uncertainty parameters for modeling obtaining forest food products, FAREASTCON, 9271204 (2020)

8. Z.V. Tsoy, D.S. Adushinov, Corbicula flour influence on egg production, III international scientific conference: agritech-iii-2020: agribusiness, environmental engineering and biotechnologies, 22017 (2020)

9. L. Kalinina, I. Zelenskaya, O. Vlasenko, Methodical approach to the assessment of food security in the region, Smart Innovation, Systems and Technologies, 172, 731-741 (2020)

10. I.A. Zelenskaya, Assessment of the development of rural areas in the region, Bulletin of the Altai Academy of Economics and Law, 10-3, 37-44 (2019)
11. L.A. Kalinina, N.V. Kalinin, I.A. Zelenskaya, O.V. Vlasenko, Problems and prospects of development of horticultural communities in russia, Agroindustrial complex: Economy, Management, 12, 25-30 (2018)

12. A.F. Zverev, S.V. Trufanova, N.N. Anikienko, Method for determining production and resource use efficiency, Smart innovation, systems and technologies, 172, 783-791 (2020)

13. L. Kalinina, I. Zelenskaya, S. Trufanova, N. Kalinin, Prospects of development of aquaculture in Russia and its regions, 1st International symposium on water resource and environmental management, wrem 2018, 01008 (2019)

14. D.S. Adushinov, A.I. Zheltikov, A.I. Kuznetsov, A.D. Adushinov, A.O. Frolenko, Comparative analysis of the exterior of culled cows of different breeds in the Baikal region, Iop conference series: Earth and environmental science, 42021 (2020)

15. A.I. Kuznetsov, D.S. Adushinov, S.S. Minnebaeva, M.L. Garmaev, The composition and properties of com milk «Siberyachka» breed depending on the method of keeping them, Iop conference series: Earth and environmental science, 32007 (2020) 